\title{
Os Mapas que Marcia me Mostrou: a metodologia do Mapa da Vida no trabalho com o teatro na comunidade
}

Aline Maria Lauermann ${ }^{1}$

Recebido em: 01/04/2020

Aprovado em: 29/04/2020

DOI: $10.5965 / 2358092521232020290$

\footnotetext{
1 Mestranda em Teatro no Programa de Pós Graduação em Teatro da Universidade do Estado de Santa Catarina (PPGT/UDESC). Licenciada em Teatro pela Universidade Federal de Santa Maria (UFSM).E-mail: lauermannaline@gmail.com
} 


\section{RESUMO}

Este relato apresenta quatro experiências distintas com a metodologia do Mapa da Vida, sendo elas uma oficina realizada no ano de 2015, o desenvolvimento do meu Trabalho de Conclusão de Curso (2017), a disciplina Teatro em Contextos Específicos (2019) e o meu estágio docência (2019). Pretendo revisitar essas experiências que contribuíram na formulação do meu entendimento sobre o trabalho no contexto comunitário, assim como refletir acerca das possibilidades pedagógicas que a metodologia oferece para aqueles que pretendem atuar nesse campo.

Palavras-chave: Mapas da Vida, teatro, comunidades, teatro comunitário.

\section{ABSTRACT}

This report presents four different experiences with the Map of Life methodology, being to a workshop held in 2015, the development of my Course Conclusion Work (2017), the discipline Theater in Specific Contexts (2019) and my internship teaching (2019). I intend to revisit these experiences that contributed to the formulation of my understanding of work in the community context, as well as reflect on the pedagogical possibilities that the methodology offers for those who intend to work in this field.

Keywords: Maps of life, theater, communities, community theater.

\section{INTRODUÇÃO}

A primeira vez que tive contato com a metodologia do Mapa da Vida foi em 2016, na ocasião a Professora Marcia Pompeo Nogueira ministrou uma oficina em que construímos nossos mapas e nele apontávamos nossas contradições. A me- 
todologia me encantou tanto que li o livro VentoForte no Teatro em Comunidade (NOGUEIRA, 2015) e decidi estudar mais sobre essa prática. Já no ano de 2017, em meu Trabalho de Conclusão de Curso (TCC), adotei os Mapas da Vida como a metodologia que guiaria meu trabalho em uma comunidade de interesse, um grupo de mulheres da rede de economia solidária intitulada $M a$ rias Bonitas: Fazendo História. E, em 2019, já na pós-graduação, novamente tive a oportunidade de retomar meu mapa a partir de outras perspectivas.

No ano de 2019 tive a felicidade de conviver com a Prof. Marcia Pompeo. Fiz uma disciplina que ela ministrou no Programa de Pós Graduação em Teatro da Universidade do Estado de Santa Catarina (PPGT/UDESC) e, depois, realizei meu estágio docência do mestrado em sua turma de Metodologia do Ensino do Teatro - Comunidade, da mesma instituição. Aqui pretendo fazer uma tentativa de olhar e refletir sobre todas as vezes que Marcia foi um ponto fundamental em meu mapa da vida, refletir sobre como essa metodologia é, podemos dizer, versátil ao trabalho comunitário, seja com crianças, adultos, jovens e idosos. Para mim é muito caro falar sobre a metodologia que me inspirou a trabalhar com comunidades, falar sobre as experiências que tive e como elas modificaram minha visão sobre o teatro e o teatro comunitário.

O Mapa da Vida "é uma atividade que integra o método de Ilo Krugli." (NOGUEIRA, 2002, p. 76) ainda que Marcia não defina precisamente em seus escritos como é realizada essa abordagem, descreve que os participantes criam artesanalmente desenhos de personagem, sejam eles próprios os personagens ou sejam criações ficcionais. Ainda descreve que o método criado por Ilo Krugli:

Representa um instrumento para o desenvolvimento das histórias criadas e de seus personagens. Em geral são propostos três mapas: o que representa o personagem antes de nascer; o que representa seu presente, incluindo seus sonhos, e o mapa do futuro. Os mapas são os caminhos dos personagens, seu passado mítico, seu presente e seu futuro [...] os participantes desenham 
a vida de seus personagens [...] cada pessoa pode criar um mapa de um personagem e o grupo pode escolher o que é mais significativo (NOGUEIRA, 2008, p. 124).

Considero que, em nossas vidas, seguimos caminhos que nem sempre são os planejados. Ora viramos à esquerda, ora à direita. Às vezes paramos e pedimos informações, pois as direções que tomamos podem nos deixar um tanto quanto confusos a respeito de qual será o ponto final da caminhada. É assim que entendo os Mapas da Vida. Sobre os momentos em que viramos a esquina ou paramos. Momentos que nos fazem refletir: de onde viemos? O que aconteceu até chegar onde estamos? Quem encontramos no caminho? O tempo de cada parada. O sentido que damos a nossas escolhas.

Se fosse fazer um mapa de minhas escolhas, o primeiro ponto seria o teatro. Depois, o das possibilidades pedagógicas do teatro, o que me levou até a comunidade. Na comunidade, os interesses pelas criações artísticas e/ou poéticas. E essas criações me levaram a querer pesquisar o teatro.

\section{PRIMEIROS MAPAS E EXPERIÊNCIAS COMU- NITÁRIAS}

No ano de 2016 tive a oportunidade de participar do V Seminário da Licenciatura em Teatro - UFSM ${ }^{2}$, que debatia acerca das relações artístico-pedagógicas do teatro e as comunidades. Neste evento, também pude participar de uma palestra proferida pela Prof. Marcia Pompeo e da oficina "Mapa da Vida". E, a partir desse momento, decidi que gostaria de pesquisar e entender melhor as práticas teatrais comunitárias.

A metodologia utilizada para o oficina mexeu muito comigo, pois estava passando por um momento de novas descobertas em relação ao feminismo. Em um determinado momento da oficina, precisávamos encontrar as contradições que estavam 
em nosso mapa, percebi que as minhas estavam justo no ponto em que destacava minha descoberta enquanto feminista. Percebi que meu discurso de liberdade, de empatia à outras muIheres, não se aplicava quando me relacionava com minha mãe.

Essa metodologia revelou a mim mesma meu lugar no mundo, me fez ter entendimento das minhas escolhas e da minha história. E ao mexer com um sentimento tão forte e de uma maneira leve, gostosa de fazer, - em que a dor ou incertezas se perdiam entre a poética e potência da criação de pequenas cenas - decidi que essa era a metodologia que eu poderia usar para trabalhar com outras mulheres. Despertou-me uma vontade de fazer oficinas de teatro para mulheres, para que elas pudessem se conhecer, se experimentar e, talvez, se redescobrir. $\mathrm{Na}$ época queria que minha mãe pudesse fazer essas oficinas, mas a distância geográfica não permitiria que eu realizasse esse projeto na cidade em que ela mora.

Em meu Trabalho de Conclusão de Curso (2017), escolhi trabalhar com uma comunidade de mulheres, conhecida como Marias Bonitas: Fazendo História. Mulheres que, em sua grande maioria, são pobres, negras e de mais idade. A comunidade desenvolve atividades de economia solidária, ações de empoderamento e com essas ações vem reduzindo e, de alguma forma, denunciando as desigualdades sociais vividas pelas mulheres residentes no Bairro Urlândia, na cidade Santa Maria/RS.

Durante o ano de 2017, todas as quartas-feiras, de maio à agosto, apenas observei a comunidade, escutei suas angústias e seus planos. O período entre agosto e setembro foi o momento em que buscamos estabelecer uma escuta de nossos corpos, em que trabalhamos com jogos e exercícios propostos por Augusto Boal. Em outubro iniciamos as oficinas dos Mapas da Vida. No início, frequentava as reuniões sem uma proposta teatral, apenas com o intuito de conhecê-las e de que elas me conhecessem. Com o tempo, começaram a consultar minha opinião sobre alguns assuntos e fui deixando de ser a "menina da universidade" e passando a ser apenas a Aline. "Um dos valiosos ensinamentos deste trabalho diz respeito ao cuidado de chegar na comunidades respeitando seu tempo, seu ritmo, o jeito de 
levar a vida de seus moradores" (NOGUEIRA, 2015, p. 7).

Percebi que ao desenvolver um trabalho, de qualquer natureza, em um contexto comunitário, devemos ter um cuidado enorme ao nos aproximarmos dessas pessoas. No trabalho com o teatro, elas não têm a obrigação de entender todas as dinâmicas ou termos que o teatro exige, como por exemplo: as roupas apropriadas, a presença de todas para a continuação dos processos de experimentação, o que é base, foco etc. Esses procedimentos, técnicas, se assim posso dizer, levam tempo para que se tornem naturais na prática com não atores. E como não estava habituada com esse tipo de abordagem, achava tudo muito demorado, então o diálogo se tornou a melhor maneira de iniciar minha prática teatral na comunidade.

Acho importante frisar que meu objetivo não era estudar as Marias Bonitas; e, sim, construir juntamente com elas possibilidades de experimentação teatral e de me experimentar como artista-docente. Procurei, em todos os momentos, ter um diálogo franco com elas, mesmo que às vezes não nos escutássemos. Desde o primeiro dia lhes contei qual era o meu objetivo e pedi que não se preocupassem com resultados, pois seriam trabalhados se surgissem ou se sentissem a necessidade de explorá-los, mas que estávamos ali para experimentar. Esse foi o convite: "Querem experimentar o teatro comigo?". A resposta me surpreendeu, não que eu achasse que fossem negar, mas pela vontade que aquele SIM representava.

Outro ponto importante é de que não sou especialista nos Mapas da Vida e na época pouco conhecia a metodologia. Na verdade, o que desenvolvi com as Marias Bonitas foi inspirado no que vivenciei na oficina da Marcia Pompeo Nogueira, no $V$ Seminário da Licenciatura em Teatro - UFSM (2016). Mesmo estudando as publicações, livros e artigos sobre esse método, ainda não tinha a dimensão da potência que poderia gerar esse trabalho. Fui adaptando algumas coisas e misturando com o que lembrava da oficina.

Antes de começar os desenhos dos mapas, passamos por dois momentos. No primeiro fizemos o mapeamento do grupo, em uma espécie de linha do tempo: "em qual ano eu nasci?". 
Aquela que era mais velha ficava em uma ponta e a mais nova em outra ponta da fila. As perguntas eram referentes ao ano de nascimento, com que idade começou a trabalhar, quando foi morar na Urlândia e quando chegou às Marias Bonitas. Por elas terem gostado da "brincadeira", abri o espaço para que elas fossem fazendo as perguntas. Foram várias revelações, muitas risadas e, com certeza, muita sinceridade. E, assim, fui instigando-as a relembrar de suas vidas, sem que fosse dolorido ou constrangedor para ninguém.

Depois, pedi que sentassem da maneira mais confortável possível e que fechassem os olhos. Perguntei: "quem sou eu? de onde eu vim? o que aconteceu até chegar aqui?". Não eram perguntas para serem respondidas, apenas para pensar. Lembrar. Após pensar sobre as perguntas, pedi que fizessem dois desenhos, o primeiro que seria sobre suas vidas, as principais escolhas que fizeram até aquele dia. O segundo, os caminhos que querem percorrer até os seus sonhos.

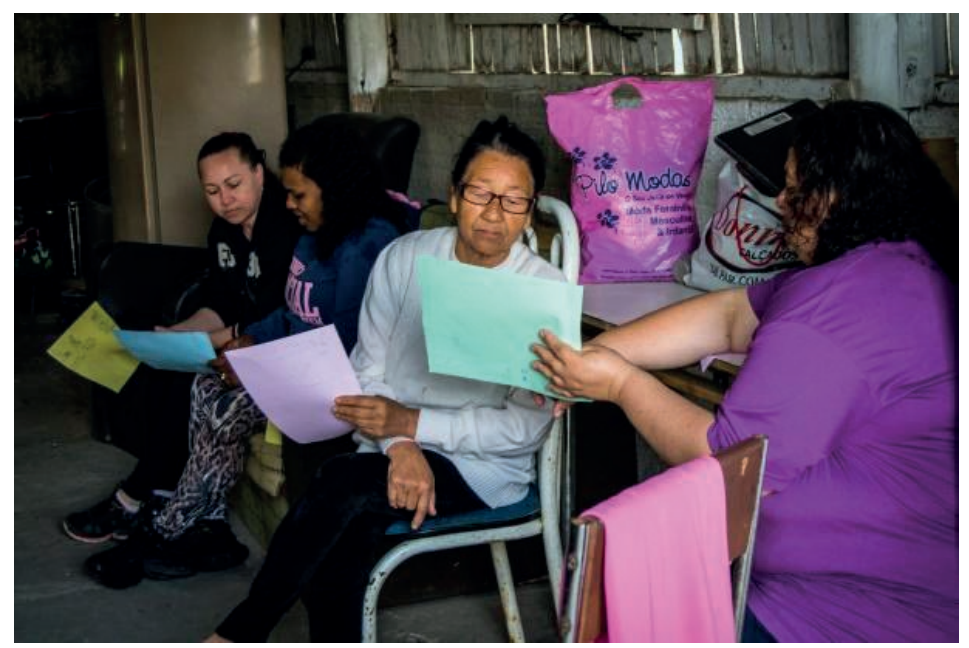

Figura 1: Oficina "Mapa da Vida" com as Marias Bonitas.

Fonte: arquivo pessoal da autora (2017). 
Trabalhar com o Mapa da Vida, é trabalhar com "sua vida atual, o que envolve os seus sonhos" (NOGUEIRA, 2015, p. 9). E dentro da comunidade percebo como uma possibilidade dar vazão às singularidades, às subjetividades, vazão poética à cada corpo e à cada história. Ter a chance de experimentar no corpo o que nossas vidas contam. E por querer experimentar no corpo suas histórias, surgiu a ideia de montarmos uma peça de teatro.

Ao compartilhar os mapas entre si, elas mesmas escolheram quais eram os aspectos que mais se identificavam entre suas histórias. E sem saber ao certo como faríamos isso, escrevemos um roteiro baseado em quatro momentos dos mapas: a infância, a adolescência, a vida adulta e o agora.

Trabalhamos durante dois meses sobre o roteiro e a criação de cenas; seria a história de uma lavadeira que queria ser poetizar, mas precisava servir ao seu pai e, depois, ao seu marido. Talvez por falta de maturidade ou experiência minha, o espetáculo não se concretizou.

Ao me interessar pelo teatro comunitário, entretanto, sabia das implicações que esse trabalho teria com aquelas mulheres. Mesmo que criassem uma expectativa sobre o resultado, o processo que elas mesmas criaram com seus corpos e entre si, foi importante para o grupo, mas isso era o suficiente para mim e não para elas. Por isso resolvemos produzir um material audiovisual com as cenas trabalhadas.

Adaptamos para o vídeo o roteiro, chamamos pessoas para filmar, editar, fotografar. E ao encerrar minha estada na comunidade, elas tiveram um resultado, um DVD para o grupo e um para cada. Sei que não se transformaram em atrizes de teatro, como a pretensão que tinham com as oficinas, mas elas são as estrelas do nosso cinema. E, até hoje, o curta é exibido pelo grupo com grande orgulho.

\section{OUTROS MAPAS}

Ao fazer a disciplina "Teatro em Contextos Específicos", 
no ano de 2019, pude revisitar a metodologia do Mapa da Vida, assim como ampliar minhas percepções sobre o teatro comunitário. Pude experimentar um viés que desconhecia, em um trabalho coletivo, que dizia muito mais do mundo que vivemos, do que de nós mesmos. Trabalhamos sobre o Poema Analfabeto Político, texto atribuído à Bertold Brecht. Quando nós fomos analfabetos políticos, quem encontramos e onde estão os analfabetos políticos que conhecemos?

O trabalho que Marcia conduziu, desenvolveu-se em torno do momento político que estávamos vivendo e dos acontecimentos mais recentes na conjuntura brasileira, como a posse de Jair Bolsonaro à presidência. Pudemos compartilhar a criação da nossa turma com o grupo Teatro Comunitário do Canto, assim como eles compartilharam conosco seu espetáculo "E se eu fosse um camarão..."4 . Pudemos jogar, compartilhar e criar juntos, como uma verdadeira comunidade teatral.

grama de Pós Graduação em Teatro da Universidade do Estado de Santa Catarina (PPGTUDESC), aos alunos especiais e regulares da pós-graduação, no primeiro semestre de 2019, pela professora Marcia Pompeo Nogueira e os Professores Colaboradores Marina Henriques Coutinho (PPGAC/PPGEAC/UNIRIO) e Tim Prentki (Winchester University) $4 \mathrm{O}$ Espetáculo “'E se eu fosse um camarão..."', do grupo de Teatro Comunitário do Canto, aborda de uma forma lúdica e bem humorada, temas vinculados à questão da expansão urbana como: a falta de espaço público de lazer; a ambição presente na especulação imobiliária e a degradação ambiental. Mais informações sobre o grupo e o espetáculo podem ser vistos em sua página nas redes sociais: https://www.facebook.com/teatrodocanto/ 


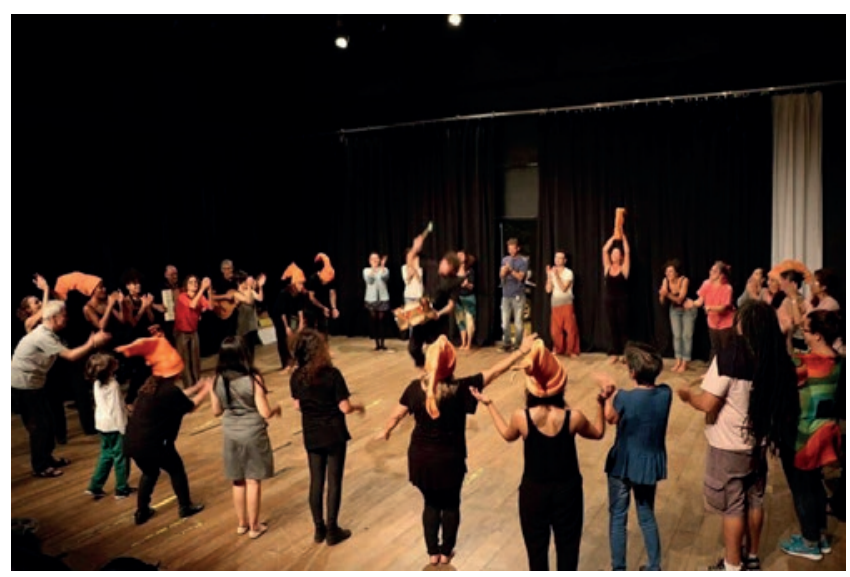

Figura 2: Alunos UDESC e o Grupo de Teatro Comunitário do Canto.

Fonte: Rede Social de Adriana Mira-Cunhã (2019).

Ao finalizar a disciplina, voltei a refletir sobre meu TCC e me surgiram várias questões sobre o meu trabalho com as Marias Bonitas e, até mesmo, sobre meu entendimento de teatro comunitário. Ao reler meu TCC e relembrar de tudo o que aprendi e vivi com as Marias Bonitas, percebi que o termo que utilizei para definir o tipo de abordagem era Teatro em Comunidade. O "em" se referia a estar em comum, ou pelo menos, à minha tentativa de me colocar em comum no processo teatral com aquelas muIheres. Mas se fosse analisar teoricamente, fundamentada pelos próprios estudos da Prof. Marcia Pompeo (2007) encontraria três definições de abordagem do teatro no contexto comunitário: Teatro para Comunidade, Teatro com Comunidade e Teatro por Comunidade. E ainda Pompeo afirma que:

Teatro na Comunidade é um fenômeno que se manifesta de diferentes formas, assumindo diferentes nomes em diferentes países: teatro popular, teatro para o desenvolvimento, teatro radical do povo, teatro para a libertação, etc. Assim como nomes diferentes podem significar a mesma coisa, nomes iguais podem significar coisas diferentes (NOGUEIRA, 2008, p. 173). 
Mas em seus escritos (NOGUEIRA, 2007) define que o Teatro para Comunidade, seria aquele que é apresentado a uma comunidade, que é apenas espectadora do resultado teatral. Que o Teatro com Comunidade é aquele em que alguém, um artista, professor conduz a comunidade numa produção teatral. E, por sua vez, o Teatro por Comunidade é quando o artista, facilitador, ou agente cultural, participa juntamente com a comunidade da experiência, vivência ou processo teatral.

\begin{abstract}
Deste modo, ao 'facilitador', 'dinamizador', 'catalisador' ou 'agente teatral' na comunidade -, mais do que conferir-lhe o papel de diretor, encenador ou coordenador, será importante que perceba e interiorize o papel de 'mediador' entre mundos, pontos de vista, histórias de vida e experiências naturalmente diferenciadas [...] a preparação destes "mediadores" em teatro e comunidade não poderá ser encarada apenas do ponto de vista do aperfeiçoamento das técnicas teatrais e da sua formação artística e estética, mas terá que ter em conta os aspectos culturais, de natureza antropológica e de análise educacional que promovam de forma mais eficaz a sua ação de mediação. Este tipo de comprometimento passa pelo investimento numa relação de longo prazo, cuidadosa e atenta a todos os sinais (BEZELGA, 2013, p. 193).
\end{abstract}

Será que minha experiência com as Marias Bonitas foi teatro com comunidade ou por comunidade? Por vezes assumi o papel de diretora teatral. Será que se perderam potências poéticas por não trabalhar enquanto facilitadora? Deveria tê-las deixado fazer mais escolhas e impor menos minha visão sobre as coisas que estávamos trabalhando? Por muitas vezes ouvi reclamarem sobre transporte público ou acesso à cidade, e por que isso não apareceu nas cenas? Será que deveria ter explorado mais as questões referentes ao lugar onde elas moram e a precariedade da periferia? Será que, de fato, minha abordagem se fixa a uma definição só? Mas em uma conversa com Marcia Pompeo, ela disse que era possível que as abordagens fluíssem entre si na medida em que se aprende a lidar com a comunidade ou, até mesmo, na medida que o trabalho exige.

Ao revisitar meu Mapa da Vida, conhecer novas maneiras 
de explorá-lo poética e cenicamente, entendi que uma das minhas falhas com as Marias Bonitas foi limitar todo nosso processo de criação a uma possibilidade. Mesmo que não conhecesse outra maneira de trabalhar com os Mapas, também não busquei experimentar novas formas. $\mathrm{E}$ isso fez com que deixasse de explorar assuntos caros à comunidade como, por exemplo, a questão da iluminação pública e do esquecimento das autoridades.

Não me preocupei com a comunidade geográfica, apenas com as Marias Bonitas. Não olhei para a cidade, nem para o bairro, apenas para as pessoas e as descontextualizei. Cabe aqui citar David Harvey em A liberdade da cidade, em que diz: "A maneira pela qual vemos nosso mundo e a maneira pela qual definimos suas possibilidades quase sempre estão associadas ao lado da cerca onde nos encontramos" (HARVEY, 2013, p. 49). Pensando nisso, percebo que transformei, a partir da visão romantizada de universitária, a Urlândia em um bairro de mulheres incríveis, um lugar de histórias incríveis - não que não fosse, ou que ainda não seja - mas esqueci de ver que é uma periferia como qualquer outra, repleta de contradições.

Talvez nem eu e nem as Marias Bonitas estivéssemos preparadas para trabalhar essas questões, mas é inevitável pensar nelas após essa disciplina. Assim como é inevitável pensar sobre as fissuras que vi, que criamos e que, por falta de experiência, deixei se fecharem.

John Holloway em Fissurar o Capitalismo propõe que para transformarmos o mundo precisamos fazê-lo a partir das fissuras, a partir das próprias brechas do sistema capitalista. Aquelas mulheres transformam a vida de mulheres do seu bairro através do artesanato, da economia solidária, de ações coletivas para gerar renda extra para cada uma e, de alguma forma, já causam fissuras no sistema. Em 2017 já me perguntava com o que o teatro poderia contribuir com aquelas mulheres? Hoje, refaço a pergunta: como eu, uma jovem de 24 anos na época, conseguiria criar mais fissuras com o teatro?

Talvez não fosse uma questão somente de criar, mas de perceber o que já acontecia. Talvez uma questão de maturidade, 
de experiência, de entendimento sobre o lugar, sobre as pessoas, sobre o próprio teatro comunitário e suas possibilidades. Poderia colocar vários talvez que me surgiram, ou citar as inúmeras incertezas do que foi meu Trabalho de Conclusão de Curso. Porém, revisitar esse lugar, após a disciplina, e poder olhá-lo com outros olhos, com certeza, me abre horizontes às novas possibilidades metodológicas de experimentação e criação, novas possibilidades de abordagem e relação com o trabalho em comunidades.

Além da disciplina que me fez revisitar meu Trabalho de Conclusão de Curso, com a Profa. Marcia Pompeo pude aprender outras abordagens com os Mapas da Vida. Estagiei na disciplina Metodologia do Ensino de Teatro III (Comunidade ${ }^{5}$ ) em que a professora abordou várias metodologias do teatro comunitário e, dentre elas, o Mapa da Vida. Observei suas aulas durante um semestre e me senti muito mais como uma aluna do que como uma docente, contribui nas discussões e facilitei alguns debates, mas meus olhos e ouvidos estavam atentos ao que ela ensinava.

Marcia sempre fez questão de que a turma, e nela eu me incluo, pudesse brincar e jogar. Ela possibilitou casamentos e separações de personagens e dessas junções criamos os mapas dos filhos dos casados, cada tio, tia, padrinho e madrinha, avós e avôs, construímos um mapa para a criança que nasceria. Ela construiu um útero gigante para que essas crianças pudessem nascer e ser apresentadas à comunidade que a turma formou, um pouco abstrato à uma lógica producente, lúdico aos olhos de jovens e de crianças, poético à que se sensibiliza aos processos coletivos. Sendo assim, percebi mais possibilidades dessa metodologia, que ela pode ser lúdica, política, subjetiva, pessoal e impessoal, ou tudo ao mesmo tempo. Que está muito mais vinculada ao grupo que se trabalha, do que a uma forma fechada. Basta que quem conduz ou facilite o processo tenha os olhos e ouvidos bem abertos para perceber o que a comunidade necessita.

5 A disciplina Metodologia do Ensino de Teatro III (Comunidade) é ofertada pelo curso de graduação em Licenciatura em Teatro da UDESC aos alunos da terceira fase da graduação. Foi ministrada pelas professoras Marcia Pompeo e Heloisa Marina da Silva, no primeiro semestre de 2019. 


\section{OBSERVAR E APRENDER}

Aprendi que o Mapa da Vida não diz respeito a somente a nossa trajetória (que até então era o que eu conhecia), pode ser o mapa de um personagem, pode ser um "ser de luz", o Mapa da Vida de quem quisermos criar, basta dar asas à imaginação e vazão poética ao que surgir. A ludicidade, o jogo, a brincadeira, principalmente a brincadeira e os cantos populares são potencializadores dessa metodologia.

Aprendi, observando, que as colocações, as provocações, as mediações e as intervenções sempre devem levar em conta cada um que estava na sala, cada um que se dispunha a aprender, a criar e a brincar. Aprendi, observando, que mesmo que tenhamos anos de experiência na área, sempre terá algo novo, que the exige um jogo de cintura. Observando, aprendi que a imaginação, a criatividade e a ludicidade de quem facilita/coordena é a melhor forma para a condução dessa metodologia. Aprendi muito observando Marcia e ainda sigo aprendendo ao ler e reler seus escritos. Hoje só nos resta agradecer sua sensível e potente forma de olhar para as comunidades e para o teatro. 


\section{REFERÊNCIAS}

BEZELGA, I. Facilitadores Teatrais nos contextos das culturas populares. In: J. Pereira, M. Vieites \& M. Lopes (coord.), Teatro do Oprimido: teorias, técnicas e metodologias para a intervenção social, cultural e educativa no século XXI, p. 187-202, 2013.

HARVEY, David. A liberdade da cidade. VAINER, Carlos; HARVEY, David; MARICATO, Ermínia, et al. Cidades rebeldes: passe livre e as manifestações que tomaram as ruas do Brasil. Col. Tinta Vermelha, Boitempo, p. 47-61, 2013.

HOLLOWAY, John. Fissurar o capitalismo. São Paulo: Publisher Brasil, 2013.

NOGUEIRA, Marcia Pompeo. Buscando uma interação teatral poética e dialética com comunidades. Urdimento-Revista de Estudos em Artes Cênicas, v. 1, n. 4, p. 70-89, 2002.

- Teatro e Comunidade. In: FLORENTINO, Adilsom; TELLES, Narciso. Cartografias do Ensino de Teatro: das idéias às práticas. Uberlândia: UDUFU, p. 173-183, 2008.

. Teatro com meninos e meninas de ruas. São Paulo: Perspectiva, 2008.

- Tentando definir o Teatro na Comunidade. Anais ABRACE, v. 8, n. 1, 2007.

Ventoforte: no teatro em comunidades. Florianópolis, SC: Letras Contemporâneas, 2015.

TEIXEIRA, Tânia Márcia Baraúna. Dimensões sócio educativas do Teatro do Oprimido Paulo Freire e Augusto Boal. Universitat Autònoma de Barcelona, 2008. 